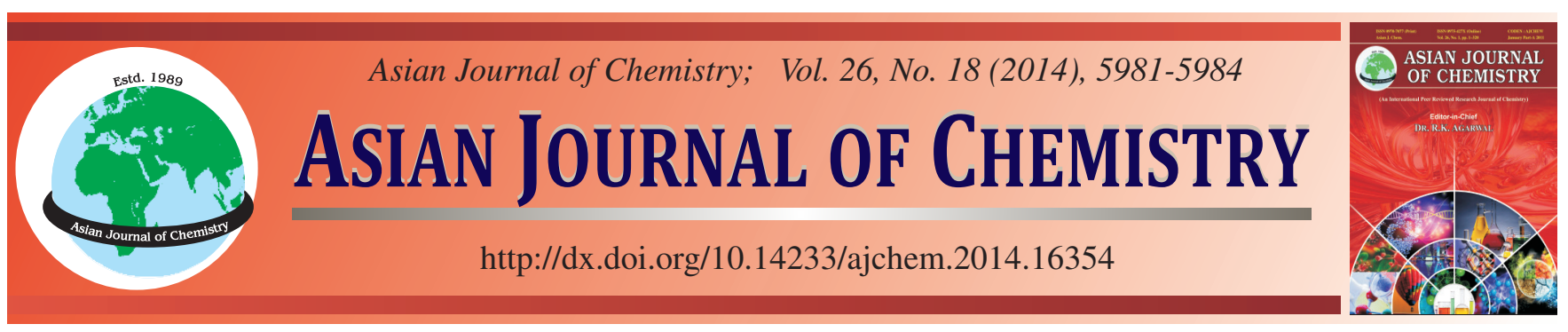

\title{
Activity of Imidazolium-Based Ionic Liquids as Catalysts for Friedel-Crafts Acylation of Aromatic Compounds
}

\author{
MingJian CAI ${ }^{*}$ and XIUGE Wang
}

Department of Chemistry, Tangshan Normal University, Tangshan, Hebei 063000, P.R. China

*Corresponding author: Fax: +86 315 3863122; Tel: +86 315 3863393; E-mail: cmj_1237@aliyun.com

Friedel-Crafts acylation of three aromatic compounds with acetyl chloride catalyzed by two kinds of ionic liquids was investigated. The imidazolium-based ionic liquids showed both high activity and high selectivity for this reaction. In particular, the catalytic effect of imidazolium-based ionic liquids was dramatically enhanced for ionic liquids containing the $\mathrm{BF}_{4}^{-}$and $\mathrm{Br}^{-}$anions. The effects of various types of anion, ionic liquid dosage, reaction temperature and time were explored using $[\mathrm{Bmim}] \mathrm{BF}_{4}$ or $[\mathrm{Bmim}] \mathrm{Br}$ as catalyst. Results show that ionic liquids can be used as both catalyst and solvent.

Keywords: Imidazolium-based ionic liquids, Acylation, Friedel-crafts, Aluminum chloride.

\section{INTRODUCTION}

Friedel-Crafts acylations are among the most important reactions because of their applications in organic syntheses in the industrial manufacture of aryl ketones. These acylation reactions are extensively used to produce pharmaceuticals, such as the nonsteroidal antiinflammatory drugs ibuprofen and naproxen. Conventionally, these reactions are catalyzed by aluminum trichloride using an acylating agent such as an acid chloride in a volatile organic solvent ${ }^{1-3}$. Given the complexation of the ketone product with aluminum trichloride, a stoichiometric excess must be used, which is then destroyed in the hydrolysis step required for product isolation ${ }^{4}$. Furthermore, the use of such homogeneous acid catalysts has some major limitations including no possible reuse, air and moisture sensitivity and low product selectivity ${ }^{5}$. As a result, one of the challenges in the field of catalysis is to replace this commonly used Lewis acid with a non-toxic, noncorrosive, easy to handle and environmentally friendly catalyst ${ }^{6}$. Considerable research efforts are being made to develop alternative suitable catalysts to overcome these drawbacks. Zeolites, clays and ionic resins and other matters are potential solid acid materials for developing catalysts to overcome above-mentioned limitations $^{7-11}$. In recent years, a growing number of organic reactions, especially catalytic ones, have been studied in different solvent systems, such as ionic liquids ${ }^{12}$. The advantages of using ionic liquids are that they are non-volatile, can dissolve a variety of compounds, can be tailor-made and can be reused ${ }^{13}$.
Ionic liquids are good solvents for many inorganic and organic compounds ${ }^{14-16}$. This property may be related to their ability to modify their chemical affinity toward a specific material simply by changing ionic nature, leading to the containment of the reaction volume.

Before they can be used commercially on an industrial scale, the process variables need to be optimized in the laboratory, not only for batch and continuous reactor systems, but also product yield and catalyst selective ability for maximum reactant conversion.

We report the alkylation of three aromatic compounds including anisole, toluene and ferrocene with acetyl chloride in the presence of dialkylimidazolium-based ionic liquids (Fig. 1). For comparison, $\mathrm{AlCl}_{3}$ was also used to catalyze the reaction.

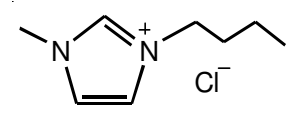<smiles></smiles>

b a $[$ Bmim $] \mathrm{C}$

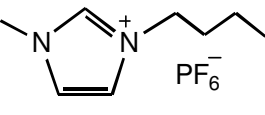

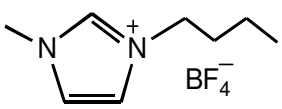

d

d $\left[\mathrm{Bmim}_{\mathrm{B}} \mathrm{BF}_{4}\right.$

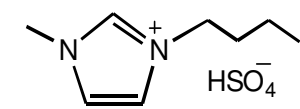

Fig. 1. Structures of the alkylimidazolium-based ionic liquids 
EXPERIMENTAL

The experiments were conducted using analytical grade chemicals without further purification. The component and distribution of the products were checked by gas chromatography/mass spectrometry (GC, Agilent 6890; MS, HewlettPackard 5973). The infrared spectra (IR) of the catalysts were detected by an infrared spectrometer (Brucher Co., Germany).

Synthesis of ionic liquid: Synthesis of ionic liquids was performed based on a modified procedure as previously described $^{17-19}$

General acylation procedure: Given amounts of mixtures of aromatic compounds and ionic liquids in ethyl acetate were placed in a $100 \mathrm{~mL}$ three-neck flask equipped with a stirrer, a reflux condenser with a drying pipe and a thermometer. An appropriate amount of a mixture of ethyl acetate and acetyl chloride was then added dropwise to the flask for 10-15 min with stirring. The acylation reaction was typically carried out for $20 \mathrm{~min}$ to $120 \mathrm{~min}$ at the desired temperature and ambient atmosphere with vigorous stirring. At the end of the reaction, the reaction mixtures were cooled to room temperature. The mixtures included two liquid phases (organic phase and ionic liquid phase). The organic layer can be easily decanted from the catalyst-ionic liquids system. Any organic residues were removed after extracting the organic phase with diethyl ether and ionic liquid can then be reused. Qualitative and quantitative analysis were conducted with GC and Fourier transform infrared spectroscopy (FT-IR). The contents of the various components were determined using the normalization method. GC-MS analyses were performed using a Hewlett Packard GC-MS 5973 with a RTX-5MS column (length $=30 \mathrm{~m}$, inner diameter $=0.25 \mathrm{~mm}$ and film thickness $=0.5 \mu \mathrm{m}$ ).

\section{RESULTS AND DISCUSSION}

The utility of ionic liquids was investigated in the acylation reactions using acetyl chloride and aromatic compounds (Scheme-I)

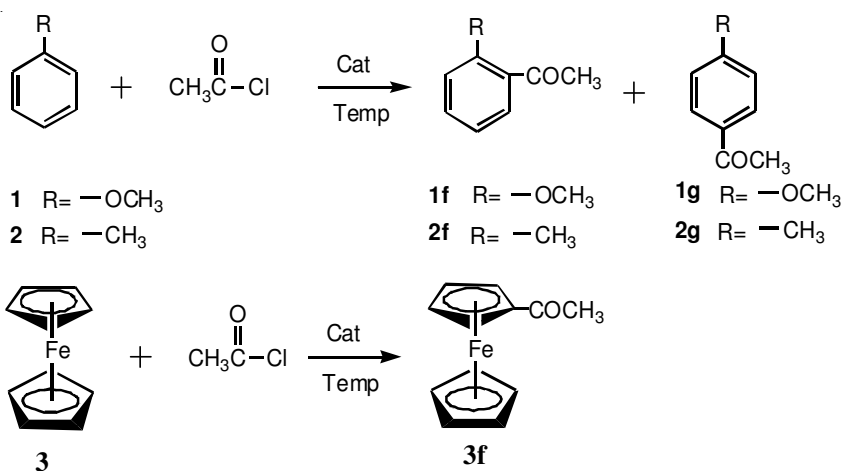

Scheme-I: Acylation reaction between aromatic compounds and acetyl chloride

Effects of the type of catalysts on reaction results: The yields and the selectivity of the acylation of aromatic compounds with acetyl chloride catalyzed by ionic liquids containing 1-butyl-3-methylimidazolium-based cations are listed in Table-1. Ionic liquids such as 1-butyl-3-methylimidazolium tetrafluoroborate $\left([\mathrm{Bmim}] \mathrm{BF}_{4}\right)$, 1-butyl-3-methylimidazolium hexafluorophosphate $\left([\mathrm{Bmim}] \mathrm{PF}_{6}\right)$ resulted in greater activity than three other ionic liquids when they were used as catalysts for compounds 1 and $\mathbf{2}$ (Table-1, entries 3, 4, 8, 9). In particular, [Bmim $] \mathrm{BF}_{4}$ (Table-1, entries 4, 9) exhibited excellent performance for acetylation of aromatic compounds. However, when we utilized 1-butyl-3-methylimidazolium bromide ([Bmim]Br) as the catalyst for compound $\mathbf{3}$, we found its catalytic activity was the most effective of all the ionic liquids. Moreover, it can be seen that the same cation and different anions of the ionic liquids have significant effects on acetylation of aromatic compounds.

TABLE-1

ACETYLATION OF AROMATIC COMPOUNDS WITH ACETYL CHLORIDE UNDER DIFFERENT TYPES OF CATALYSTS

\begin{tabular}{ccccc}
\hline Entry & $\begin{array}{c}\text { Aromatic } \\
\text { compounds }\end{array}$ & Acetyl chloride & Catalyst & $\begin{array}{c}\text { Overall Yield } \\
\text { of alkylate (\%) }\end{array}$ \\
\hline 1 & $\mathbf{1}$ & $\mathrm{CH}_{3} \mathrm{COBr}$ & $\mathbf{a}$ & 23.2 \\
2 & $\mathbf{1}$ & $\mathrm{CH}_{3} \mathrm{COBr}$ & $\mathbf{b}$ & 25.4 \\
3 & $\mathbf{1}$ & $\mathrm{CH}_{3} \mathrm{COBr}$ & $\mathbf{c}$ & 59.4 \\
4 & $\mathbf{1}$ & $\mathrm{CH}_{3} \mathrm{COBr}$ & $\mathbf{d}$ & 62.6 \\
5 & $\mathbf{1}$ & $\mathrm{CH}_{3} \mathrm{COBr}$ & $\mathbf{e}$ & 40.7 \\
6 & $\mathbf{2}$ & $\mathrm{CH}_{3} \mathrm{COBr}$ & $\mathbf{a}$ & 20.6 \\
7 & $\mathbf{2}$ & $\mathrm{CH}_{3} \mathrm{COBr}$ & $\mathbf{b}$ & 21.2 \\
8 & $\mathbf{2}$ & $\mathrm{CH}_{3} \mathrm{COBr}$ & $\mathbf{c}$ & 56.5 \\
9 & $\mathbf{2}$ & $\mathrm{CH}_{3} \mathrm{COBr}$ & $\mathbf{d}$ & 58.3 \\
10 & $\mathbf{2}$ & $\mathrm{CH}_{3} \mathrm{COBr}$ & $\mathbf{e}$ & 33.4 \\
11 & $\mathbf{3}$ & $\mathrm{CH}_{3} \mathrm{COBr}$ & $\mathbf{a}$ & 33.2 \\
12 & $\mathbf{3}$ & $\mathrm{CH}_{3} \mathrm{COBr}$ & $\mathbf{b}$ & 41.5 \\
13 & $\mathbf{3}$ & $\mathrm{CH}_{3} \mathrm{COBr}$ & $\mathbf{c}$ & 39.8 \\
14 & $\mathbf{3}$ & $\mathrm{CH}_{3} \mathrm{COBr}$ & $\mathbf{d}$ & 28.1 \\
15 & $\mathbf{3}$ & $\mathrm{CH}_{3} \mathrm{COBr}$ & $\mathbf{e}$ & 25.2 \\
\hline
\end{tabular}

Reaction conditions: molar ratio aromatic compounds/acetyl chloride $=$ $1: 1.1 ; \mathrm{W}_{\text {cat }}=20 \% ; \mathrm{T}=$ reflux temp; $\mathrm{t}=1 \mathrm{~h}$. a. Overall Yield is the sum of $p$ - and $o$-isomer

To acquire more information on the reaction performances of ionic liquids as catalysts, aluminum chloride was used for comparison. The results are summarized in Table-2. Comparing Tables-1 and 2, it is observed that better results are obtained with ionic liquids instead of aluminum chloride (Table-1, entries 3, 4, 8, 9, Table-2, entries 1, 7). In addition, better results were obtained with ionic liquids in the presence of aluminum chloride (Table-2, entries 4, 5, 10, 11, 14, 15). Therefore, the performance of mixed catalyst is better than that of single aluminum chloride catalyst, with some exceptions (Table-2, entries 2, 3, 6, 8, 9, 12, 16-18). Nevertheless, it can still be concluded that the catalytic activity of mixed catalyst containing $[\mathrm{Bmim}] \mathrm{BF}_{4}$ is superior to that of any other combined catalyst in the acetylation of compounds $\mathbf{1}$ and $\mathbf{2}$.

Effects of the dosage of catalysts on reaction results: We also evaluated the effect of $[\mathrm{Bmim}] \mathrm{BF}_{4}$ and $[\mathrm{Bmim}] \mathrm{Br}$ ionic liquids in different amounts at the same temperatures. The initial experiments were carried out with $10 \%$ (wt \%) of ionic liquids using aromatic compounds and acetyl chloride at reflux temperature. Fig. 2 shows the result for experimental investigations under the specified conditions. The activation began almost from the start of addition of the catalyst. As expected, a slight conversion to the corresponding acylation was observed in the ionic liquid, even with a small amount of catalyst. Furthermore, the yield was raised by increasing the amount of catalyst. When the content of ionic liquid reached 


\begin{tabular}{|c|c|c|c|c|}
\hline \multicolumn{5}{|c|}{$\begin{array}{c}\text { TABLE-2 } \\
\text { ACETYLATION OF AROMATIC COMPOUNDS WITH ACETYL } \\
\text { CHLORIDE UNDER MIXED CATALYSTS }\end{array}$} \\
\hline Entry & $\begin{array}{l}\text { Aromatic } \\
\text { compound }\end{array}$ & $\begin{array}{l}\text { Acetyl } \\
\text { chloride }\end{array}$ & Catalyst & $\begin{array}{c}\text { Overall Yield } \\
\text { of alkylate (\%) }\end{array}$ \\
\hline 1 & 1 & $\mathrm{CH}_{3} \mathrm{COBr}$ & $\mathrm{AlCl}_{3}$ & 51.8 \\
\hline 2 & 1 & $\mathrm{CH}_{3} \mathrm{COBr}$ & a- $\mathrm{AlCl}_{3}$ & 35.2 \\
\hline 3 & 1 & $\mathrm{CH}_{3} \mathrm{COBr}$ & b- $\mathrm{AlCl}_{3}$ & 38.8 \\
\hline 4 & 1 & $\mathrm{CH}_{3} \mathrm{COBr}$ & c- $-\mathrm{AlCl}_{3}$ & 62.3 \\
\hline 5 & 1 & $\mathrm{CH}_{3} \mathrm{COBr}$ & d- $-\mathrm{AlCl}_{3}$ & 66.2 \\
\hline 6 & 1 & $\mathrm{CH}_{3} \mathrm{COBr}$ & e- $\mathrm{AlCl}_{3}$ & 49.6 \\
\hline 7 & 2 & $\mathrm{CH}_{3} \mathrm{COBr}$ & $\mathrm{AlCl}_{3}$ & 47.1 \\
\hline 8 & 2 & $\mathrm{CH}_{3} \mathrm{COBr}$ & a- $\mathrm{AlCl}_{3}$ & 34.2 \\
\hline 9 & 2 & $\mathrm{CH}_{3} \mathrm{COBr}$ & b- $\mathrm{AlCl}_{3}$ & 36.2 \\
\hline 10 & 2 & $\mathrm{CH}_{3} \mathrm{COBr}$ & c- $-\mathrm{AlCl}_{3}$ & 56.3 \\
\hline 11 & 2 & $\mathrm{CH}_{3} \mathrm{COBr}$ & d- $-\mathrm{AlCl}_{3}$ & 59.6 \\
\hline 12 & 2 & $\mathrm{CH}_{3} \mathrm{COBr}$ & e- $\mathrm{AlCl}_{3}$ & 44.8 \\
\hline 13 & 3 & $\mathrm{CH}_{3} \mathrm{COBr}$ & $\mathrm{AlCl}_{3}$ & 42.9 \\
\hline 14 & 3 & $\mathrm{CH}_{3} \mathrm{COBr}$ & a- $\mathrm{AlCl}_{3}$ & 45.1 \\
\hline 15 & 3 & $\mathrm{CH}_{3} \mathrm{COBr}$ & b- $\mathrm{AlCl}_{3}$ & 48.4 \\
\hline 16 & 3 & $\mathrm{CH}_{3} \mathrm{COBr}$ & c- $-\mathrm{AlCl}_{3}$ & 42.3 \\
\hline 17 & 3 & $\mathrm{CH}_{3} \mathrm{COBr}$ & d- $-\mathrm{AlCl}_{3}$ & 32.6 \\
\hline 18 & 3 & $\mathrm{CH}_{3} \mathrm{COBr}$ & e- $\mathrm{AlCl}_{3}$ & 30.9 \\
\hline
\end{tabular}

Reaction conditions: molar ratio aromatic compound/acetyl chloride $=$ $1: 1.1 ; \mathrm{W}_{\text {cat }}=20 \% ; \mathrm{T}=$ reflux temp; $\mathrm{t}=2 \mathrm{~h}$

20 to $30 \%$, the yield reached its maximum levels, which were $65.6 \%$ (anisole, wt \%) and $42.1 \%$ (ferrocene, wt \%). After that, the yield remained unchanged or decreased with the increase in the content of catalyst.

According to the mechanism of Friedel-Crafts acylation, increasing the catalyst increases the concentration of acyl cations, hastening the reaction. The conversion of aromatic compound would therefore increase. Unexpectedly, a series of side reactions also took place simultaneously and a decrease in the yield occurred when the catalyst was more than $30 \%$ of the total mass of reactants. It can be readily seen that $\mathrm{W}_{\text {cat }}$ is crucial for the acylation reaction. Taking all of these factors into account, the value of 20 to $30 \% \mathrm{~W}_{\text {cat }}$ was suitable.

Effect of catalyst on selectivity of the production: Results of acylation of aromatic compound with acetyl chloride in ionic liquid system are shown in Table-3. Scheme-I shows that $o$-and $p$-position isomer products (Scheme-I, 1-2f, 1-2g) were obtained in these acylations. We expected $p$-substituted aromatic compounds to be the major products because of steric hindrance. As expected, the $p$-isomer is the major product when ionic liquids were used as catalysts for acylation. In addition

\begin{tabular}{ccccc}
\multicolumn{5}{c}{ TABLE 3 } \\
Fntry & Reactant & Catalyst & $\begin{array}{c}\text { Major } \\
\text { product } \\
\text { yield }(\%)^{\mathrm{C}}\end{array}$ & $\begin{array}{c}\text { Selectivity } \\
\text { to major } \\
\text { product }(\%)^{\mathrm{c}}\end{array}$ \\
\hline 1 & $\begin{array}{c}\text { Anisole + acetyl } \\
\text { chloride }\end{array}$ & {$\left[\mathrm{Bmim}_{\mathrm{B} F}\right.$} & 65.3 & 90.5 \\
2 & $\begin{array}{c}\text { Toluene + acetyl } \\
\text { chloride }\end{array}$ & {$\left[\mathrm{Bmim}_{4} \mathrm{BF}_{4}\right.$} & 62.5 & 92.3 \\
3 & $\begin{array}{c}\text { Ferrocene }+ \\
\text { acetyl chloride }\end{array}$ & {$[\mathrm{Bmim}] \mathrm{Br}$} & 42.8 & 100 \\
\hline
\end{tabular}

Reaction conditions: molar ratio aromatic compound/acetyl chloride $=$ $1: 1.1 ; \mathrm{W}_{\text {cat }}=20 \% ; \mathrm{T}=$ reflux temp; $\mathrm{t}=2 \mathrm{~h}$. $\mathrm{b}$. Major product is $p$ isomer; c. refer to the molar ratio of $p$ - to $o$ - isomer

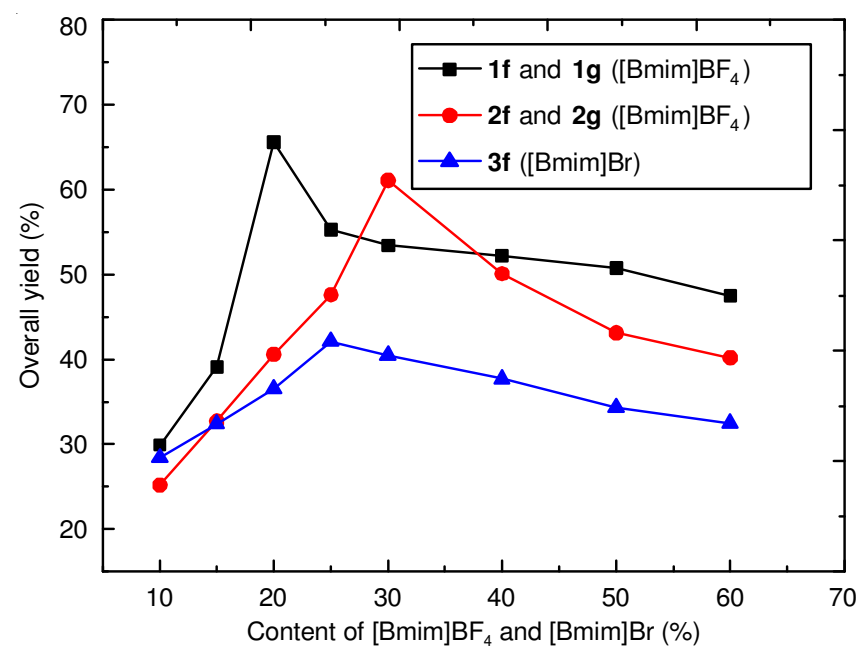

Fig. 2. Acetylation of aromatic compounds with acetyl chloride under different dosages of catalysts. Reaction conditions: molar ratio aromatic compound/acetyl chloride $=1: 1.1 ;$ Temp. $=$ reflux temp; Time $=2 \mathrm{~h}$

to the steric hindrance, there may be other factors causing the phenomenon, which is the next step.

Effect of reaction temperature and time on acylation reaction results: Reaction temperature has an important effect on reaction dynamics and thermodynamics. Therefore, the effect of reaction temperature on the results of acylation reaction catalyzed by $[\mathrm{Bmim}] \mathrm{BF}_{4}$ or $[\mathrm{Bmim}] \mathrm{Br}$ was investigated. The influence of reaction temperature on the overall yield is shown in Fig. 3. A dramatic effect on the yield of acylated products was observed. Raising the reaction temperature accelerated the molecular thermal agitation and the molecular collision probability between acylium cation and aromatic ring. Therefore, the acylation reaction was hastened and high yields of $65.9 \%$ (anisole), $51.3 \%$ (ferrocene) and $62.5 \%$ (toluene) for aromatic compounds at 40 to $70{ }^{\circ} \mathrm{C}$ were achieved. If the reaction temperature was raised further, the conversion of aromatic compounds would have decreased. In light of optimum conversion and energy consumption, $40{ }^{\circ} \mathrm{C}$ (ferrocene), $50{ }^{\circ} \mathrm{C}$ (anisole) and $60{ }^{\circ} \mathrm{C}$ (toluene) are the optimal reaction temperatures for acylation of aromatic compounds.

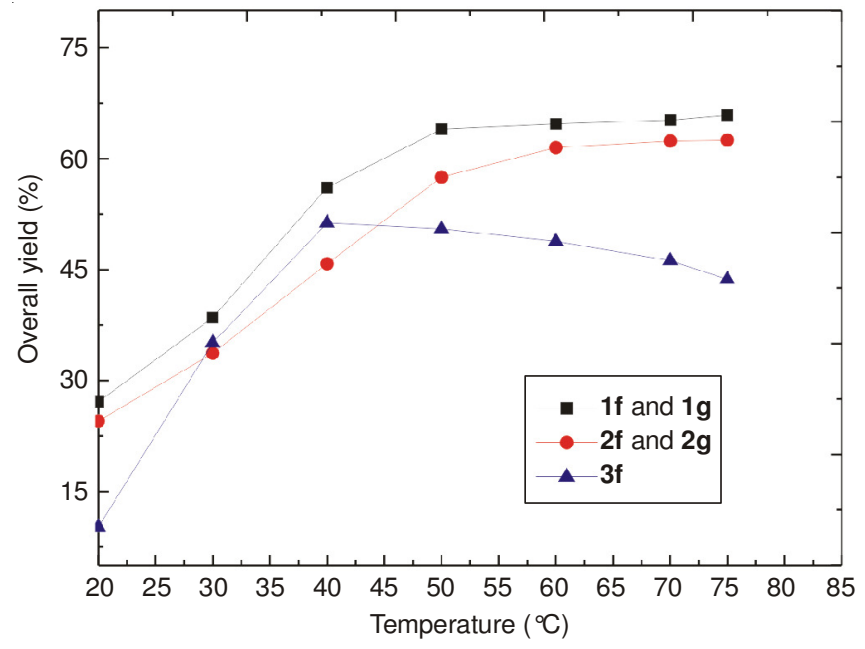

Fig. 3. Effect of reaction temperatures on the acylation reactions of aromatic compounds with acetyl chloride. Reaction conditions: molar ratio aromatic compound/acetyl chloride $=1: 1.1 ; \mathrm{W}_{\text {cat }}=20 \%$; time $=1 \mathrm{~h}$ 
The effect of reaction time was studied at a range of 20 to $120 \mathrm{~min}$. The results show that increasing the reaction time from 20 to 40 min caused a noticeable increase in the yield of 5-benzoylacenaphthene. Further increase in reaction time from 40 to 120 min no longer had an effect on the yield (Fig. 4).

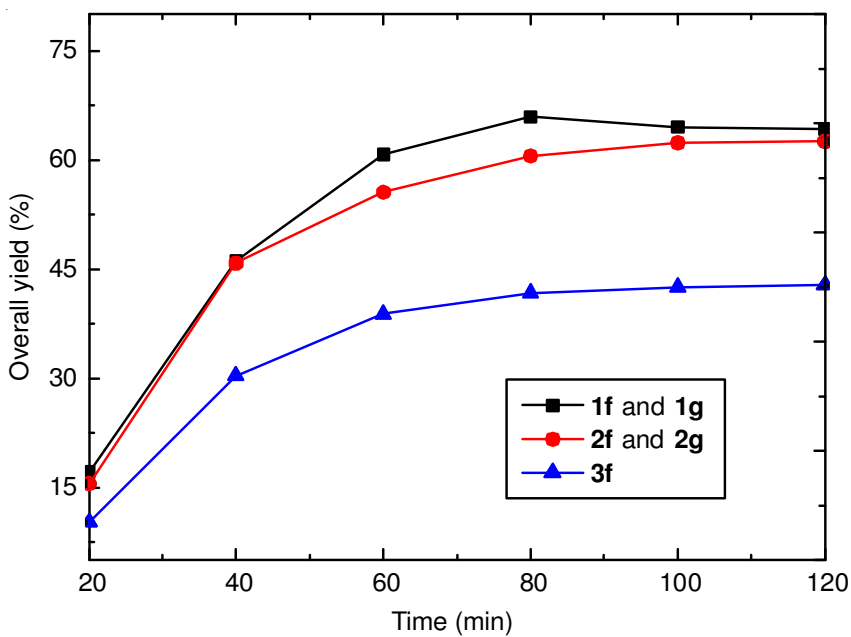

Fig. 4. Effect of reaction time on the acylation reactions of aromatic compounds with acetyl chloride. Reaction conditions: molar ratio aromatic compound/acetyl chloride $=1: 1.1 ; \mathrm{W}_{\text {cat }}=20 \% ; \mathrm{T}=$ reflux temperature

Reuse of the ionic liquid: As one of the most active Lewis acidic ionic liquid catalysts in our work, $\left[\mathrm{Bmim}^{-} \mathrm{BF}_{4}\right.$ was selected to investigate reusability. After the reaction, the mixture separated into two liquid phases, namely, the organic phase (unreacted reactants and products phase) and the $\left[\mathrm{Bmim}^{\mathrm{B}} \mathrm{BF}_{4}\right.$ ionic liquid phase. $[\mathrm{Bmim}] \mathrm{BF}_{4}$ was reused after extracting the organic phase with diethylether. The notation Rn indicates that the ionic liquid has been used $\mathrm{n}$ times. As shown in Fig. 5, there is a slow decrease in the major product yield with the increase of frequency of use. The quality and yield of acylation varied slowly in the four runs and then dropped dramatically

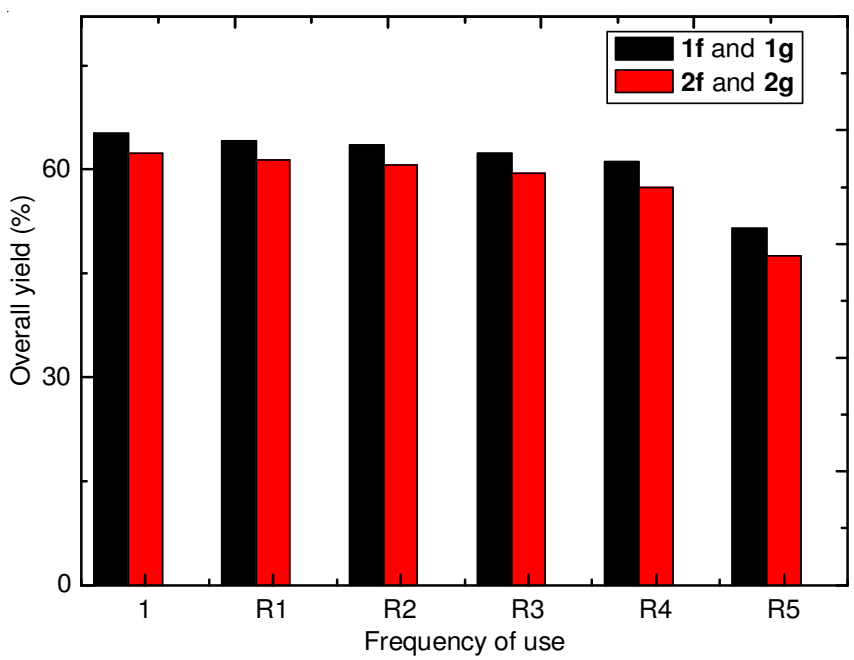

Fig. 5. Reuse of the ionic liquid. Reaction conditions: molar ratio aromatic compound/acetyl chloride $=1: 1.1 ; \mathrm{W}_{\text {cat }}=20 \%$; Temp. $=$ reflux temp; Time $=2 \mathrm{~h}$ after the fifth run. The color of the catalyst changed from light yellow into brown because of the accumulation of color materials. Furthermore, the volume of the catalyst was reduced as the number of use is increased, which may be due to the vaporization of catalyst or its dissolution in the alkylate during the post-treatment operation.

\section{Conclusion}

The acylations of aromatic compounds with acetyl chloride were carried out in a series of imidazolium ionic liquids, including its mixture with $\mathrm{AlCl}_{3}$. The ionic liquids $[\mathrm{Bmim}] \mathrm{BF}_{4}$ and $[\mathrm{Bmim}] \mathrm{Br}$ are the most suitable media for Friedel-Crafts acylation of aromatic compounds. In addition, the selectivity of target products increased. The effects of various parameters such as temperature, type of catalyst, catalyst loading and other factors on aromatic compound conversion and on product selectivity were studied. Although the mechanism of acylation reaction catalyzed by $[\mathrm{Bmim}] \mathrm{BF}_{4}$ and $[\mathrm{Bmim}] \mathrm{Br}$ ionic liquids is not clear. This research indicates that $\left[\mathrm{Bmim}^{\mathrm{B}}\right] \mathrm{BF}_{4}$ and [Bmim]Br can be used as a novel environmentally friendly catalyst and solvent for anisole, toluene and ferrocene acylation reactions. Applications of the imidazolium-based ionic liquids as solvents or catalysts for other reactions are under investigation.

\section{REFERENCES}

1. G. Olah, in Friedel-Crafts and Related Reactions, Wiley Interscience: New York and London, Vols. I-IV (1963-1964).

2. H. Szmant, Organic Building Blocks of the Chemical Industry, Wiley, New York (1989)

3. J. March, Advanced Organic Chemistry, Wiley, New York, edn 4 (1992).

4. C. Hardacre, S.P. Katdare, D. Milroy, P. Nancarrow, D.W. Rooney and J.M. Thompson, J. Catal., 227, 44 (2004).

5. S.K. Jana, Catal. Surv. Asia, 9, 25 (2005).

6. C. Paun, C. Stere, S.M. Coman, V.I. Parvulescu, P. Goodrich and C. Hardacre, Catal. Today, 131, 98 (2008).

7. V.N. Sheemol, B. Tyagi and R.V. Jasra, J. Mol. Catal. A., 215, 201 (2004).

8. G. Wine, C. Pham-Huu and M. Ledoux, Catal. Commun., 7, 768 (2006).

9. P.T. Patil, K.M. Malshe, P. Kumar, M.K. Dongare and E. Kemnitz, Catal. Commun., 3, 411 (2002).

10. P. Laidlaw, D. Bethell, S.M. Brown and G.J. Hutchings, J. Mol. Catal. A, 174, 187 (2001).

11. D.Q. Zhou, Y.H. Zhang, M.Y. Huang and Y.Y. Jiang, Polym. Adv. Technol., 14, 360 (2003).

12. V.I. Parvulescu and C. Hardacre, Chem. Rev., 107, 2615 (2007).

13. (a) P. Wasserscheid and T. Welton, Ionic Liquids in Synthesis, WileyVCH, Weinheim, edn 2 (2008); (b) C. Chiappe and D. Pieraccini, J. Phys. Org. Chem., 18, 275 (2005).

14. R. Sheldon, Chem. Commun., 2399 (2001).

15. J.G. Huddleston and R.D. Rogers, Chem. Commun., 1765 (1998).

16. Z. Liu, Z.C. Chen and Q.G. Zheng, Org. Lett., 5, 3321 (2003).

17. Y. Yu, L. Hua, W. Zhu, Y. Shi, T. Cao, Y. Qiao and Z. Hou, Synth. Commun., 43, 1287 (2013).

18. A. Parmar, V.K. Aswal and P. Bahadur, Spectrochim. Acta A, 97, 137 (2012).

19. P. Wasserscheid, M. Sesing and W. Korth, Green Chem., 4, 134 (2002). 